\title{
Analysis of lubricant performance in punching and blanking
}

\author{
Moghadam, M.; Villa, M.; Moreau, P.; Dubois, A.; Dubar, L.; Nielsen, C. V.; Bay, N.
}

Published in:

Tribology International

Link to article, DOI:

10.1016/j.triboint.2019.105949

Publication date:

2020

Document Version

Peer reviewed version

Link back to DTU Orbit

Citation (APA):

Moghadam, M., Villa, M., Moreau, P., Dubois, A., Dubar, L., Nielsen, C. V., \& Bay, N. (2020). Analysis of lubricant performance in punching and blanking. Tribology International, 141, [105949].

https://doi.org/10.1016/j.triboint.2019.105949

\section{General rights}

Copyright and moral rights for the publications made accessible in the public portal are retained by the authors and/or other copyright owners and it is a condition of accessing publications that users recognise and abide by the legal requirements associated with these rights.

- Users may download and print one copy of any publication from the public portal for the purpose of private study or research.

- You may not further distribute the material or use it for any profit-making activity or commercial gain

- You may freely distribute the URL identifying the publication in the public portal

If you believe that this document breaches copyright please contact us providing details, and we will remove access to the work immediately and investigate your claim. 


\title{
Analysis of lubricant performance in punching and blanking
}

\author{
M. Moghadam ${ }^{a}$, M. Villa ${ }^{a}$, P. Moreau ${ }^{b}$, A. Dubois ${ }^{b}$, L. Dubar ${ }^{b}$, C. V. Nielsen ${ }^{a}$ and N. Bay ${ }^{a}$ \\ aDepartment of Mechanical Engineering, Technical University of Denmark, Kongens Lyngby, \\ Denmark \\ ' Université Polytechnique Hauts de France, CNRS UMR 8201, LAMIH, Institut Carnot ARTS, F- \\ 59313 Valenciennes, France
}

\section{Abstract}

Punching and blanking processes are characterized by severe tribological conditions due to the creation of virgin surfaces, which are highly prone to develop pick-up of workpiece material on the punch surface. Hazardous forming lubricants are, therefore, commonly used in punching and blanking processes for avoidance of wear induced process deviations such as diminished surface quality, reduced dimensional accuracy and reduced tool life. The present study characterizes the function and performance of lubricants used for punching and blanking operations for assessment of the tribological lubricant properties necessary for adaption of environmentally friendly lubricant alternatives. Analysis of the tribochemical properties of the studied lubricants indicate that an applicable temperature range and a high load bearing capacity are central lubricant properties necessary for ensuring sufficient lubricating ability for punching and blanking operations. 


\section{Introduction}

Blanking and punching are the most commonly used severing process in sheet metal forming, often combined with other forming operations as an intermediate or finishing production step. Contrary to most common sheet metal forming operations, blanking and punching operations generate new, virgin surfaces during the process, which combined with the frictional stress exerted on the punch stem during the backstroke create severe tribological conditions. Sheet materials with high affinity for adhesion with tool steel, such as stainless steels, are therefore prone to cause local pick-up on the punch stem. The formation of local weld junctions on the punch stem causes scoring of the workpiece material in subsequent strokes and can introduce large tensile stresses in the punch during the backstroke, which can lead to tool failure. Millard and Gasnier [1] evaluated the lubricant performance in punching by determining the coefficient of friction (COF) from measurements of the backstroke force and theoretical analysis of the normal stresses exerted on the punch surface. Pfaff [2] reported that the backstroke force in punching is governed by the accumulation of pick-up of wear particles from the workpiece sheet on the punch stem. No further correlation was however found between the development of the wear mechanism and the measured backstroke force, due to scattering of the force measurements, possibly caused by vibrations stemming from the transducer design. Lind et al. [3] proposed that the wear mechanism occurring in a blanking process is characterized by three distinct phases where abrasive wear, adhesive wear and growth of 
friction junctions are respectively dominant. Olsson et al. [4-6] conducted extensive investigations on wear and lubrication in punching. The studies showed that the mechanism of lubrication in punching is governed by the lubricant retained on the surface of the punch stem and by the chemical interaction of the lubricant additives with the punch and sheet material. This was evaluated by testing punches with different punch tip geometries and surface topographies combined with different lubricant formulations. It was found that a tangential texture on the punch stem combined with a high viscosity lubricant reduced the amount of wear developed on the punch stem during testing. In case of efficient, additivated lubricants, however, this lubrication mechanism was of no importance. The studies furthermore showed that the development of the backstroke force with number of strokes gave a good indication of the severity of the developed wear on the punch stem and that the punching test requires lubricants with strong boundary films, such as chlorine based additives, to avoid excessive wear on the punch stem [7]. Klocke et al. [8] conducted a series of comparative analyses for characterization of different additives for evaluation of the applicability of non-chlorinated lubricants in fine blanking processes. The study showed that characterization of the tribochemical effect of single and compound additives enables optimization of the tribosystem for fine blanking processes by utilizing the synergy of the different types of additives. Hogmark et al. [9] studied the wear behavior of AISI D2 tool steel punches with sheet material of different steel grades. The study concluded that the material properties of the workpiece materials 
greatly influence the wear profile of the punch tools. Hogmark et al. highlighted material properties of ductility and hard particle phases to be decisive for promotion of adhesion, fatigue and abrasion. A number of recent investigations [10-15] have furthermore studied the applicability of tool coatings for prolonging the life of punching tools. Klocke and Raedt [16] presented a study, where the formulation and testing of different hard ceramic CVD and PVD coatings were done for cold forging and fine blanking applications. The aim was to minimize the need for hazardous lubricant additives and workpiece pretreatment. Several mechanical and thermal coating properties, such as strong adhesion of the coating to the substrate and a high thermal conductivity, were highlighted as critical coating properties in order to withstand the imposed tribological loads of the fine blanking and cold forging processes. Klocke and Raedt furthermore proposed that a low Young's modulus could increase durability of the tool coating due to reduced tensile stresses in the coating. Kitamura et al. [17] studied the tribological behavior of a micro-dimpled punch, which was evaluated by measuring the backstroke force. They found that a micro-dimpled punch texture made with a pico-second laser could drastically reduce the frictional stress exerted on the punch during the backstroke. The surface texture was optimized in terms of dimple depth, coverage and arrangement.

Many sheet metal forming tribosystems are exposed to high contact temperatures due to the mechanical work and the frictional heat introduced by the forming process. High temperatures can introduce severe tribological loads on the tribosystem due to 
decomposition of the lubricant additives as well as thinning and evaporation of the lubricant. Analysis of the tribochemical properties of the lubricant additives and the base oil can therefore give valuable information of the lubricant behavior in forming processes. Important properties include thermal stability, volatility and the tribological nature of the film forming additives in the lubricant [18,19]. Differential thermal analysis (DTA) is a commonly used technique for analysis of the influence of temperature on the tribochemical behavior of organic materials by measurement of heat flow and the change in weight at elevated temperatures, from which the occurrence of exothermic and endothermic reactions can be evaluated. Matveevsky [20-24] presented a series of investigations on the performance of different lubricant additives at high temperatures with DTA combined with different simulative tests. Matveevsky furthermore characterized the lubricant action with thermogravimetric (TG) measurements, for quantification of the maximum loss of weight during testing and the weight loss at the temperature of chemical reaction between the lubricant additives and the metal surface. For analysis of the film forming action of different lubricant additives, Matveevsky highlighted the importance of two main transition temperature points. At the first transition, the chemically active lubricant additives react with the metal surface resulting in a sharp decrease in the COF. At the second transition, the chemically modified layer loses its lubricating properties due to desorption of polar molecules or melting of chemically reacted tribofilms, which results in a subsequent increase in the COF. 
Matveevsky furthermore highlighted the possibility of using detected exothermic reactions for evaluation of the critical transition temperatures, where the lubricant additives form a surface film on the metal. Kawamura and Fujita [25] studied the performance of organic sulphur and phosphorus compounds with DTA combined with a cross-pin wear tester. The wear scar diameter of the lubricant containing sulphur additives increased with increased reactivity of the lubricant additives. The wear scar diameter generated when lubricating with phosphite based EP additives was however found to decrease linearly with increasing reaction starting temperatures. A similar observation was later made by Wan and Xue [26], who studied the performance of phosphorus based lubricant additives for lubrication of aluminum. They indicated that the tribochemical reaction between the EP additive and the sliding surface was initiated by a flash temperature generated in the rubbing action. Kawamura [27] later presented a similar correlation between additive reactivity and wear scar diameter with ZDDP additives. DTA was similarly used by Møller et al. [28,29] for studying the tribological performance of chlorinated paraffin and diakyl-polysulfide for ironing of stainless steel. The study highlighted that the EP performance of chlorinated paraffins is strongly connected to its high chemical reactivity with the main components of stainless steel, i.e. iron, chromium and nickel.

As mentioned above, blanking processes exhibit severe tribological conditions, where insufficient lubricant quality leads to heavy pick-up of workpiece material on the punch 
resulting in poor surface quality, reduced dimensional accuracy and a shortened tool life. Hazardous lubricants are therefore often used in order to facilitate stable production conditions. For minimization of the use of hazardous lubricants, the present study aims to evaluate the primary lubricant properties needed to ensure proper lubrication in punching and blanking processes, for assessment of the applicability of alternative environmentally benign lubricants. The study is based on the following individual analyses:

- Punching test

- High temperature pin-on-disc test

- Four-ball test

- Thermo-gravimetric/differential thermal analysis (TG/DTA)

- Analysis of lubricant composition with XRF

- Numerical modeling of the punching process

These tests are described in the following. 


\section{Experimental methods}

\section{Punching test}

A series of punching tests were conducted with a $1 \mathrm{~mm}$ EN 1.4301 stainless steel sheet and $\varnothing 2 \mathrm{~mm}$ PM tool steel AISI M3:2 punches with $10 \mu \mathrm{m}$ radial clearance between the punch and the die. The narrow clearance results in a large hydrostatic pressure in the shear band region that induces severe stressing of the lubricant film and promotes a large blank zone similar to the forming conditions in a fine blanking operation. The punches used for the test had a tangential surface texture of $\mathrm{Rz}=2.5 \mu \mathrm{m}$ obtained by round grinding. The punch test was conducted on a $320 \mathrm{kN} \mathrm{C}$-frame eccentric press with a stroke rate of 170 RPM and a corresponding punch speed of approximately $45 \mathrm{~mm} / \mathrm{s}$ during punching. The eccentric press was equipped with an automated pneumatic feeding system that enables continuous drawing of the sheet material from a coil for testing of several consecutive strokes. An overview of the test stand is shown in fig.1. The punch force and the backstroke force were acquired during testing with a piezoelectric load transducer. For the punching tests, lubricant was applied to the surface of the sheet metal by using roller 
lubricators. Inspection of the surface structure of the punches after testing was done with an FEI Inspect ${ }^{\mathrm{TM}}$ S50 SEM.

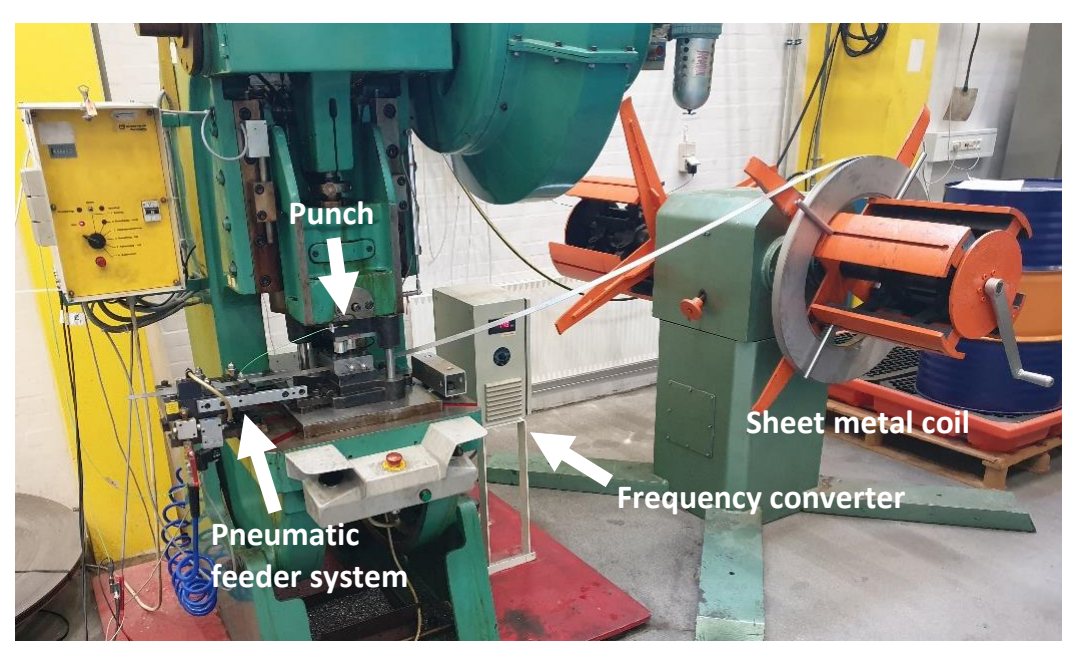

Figure 1: Eccentric press equipped with punching tool, feeder system and a load cell for measurement of the punch force and the backstroke force.

\section{High temperature pin-on-disc test}

A high temperature pin-on-disc test was carried out on the Bruker Universal Mechanical Tester Tribolab ${ }^{\mathrm{TM}}$. The $\varnothing 69.85 \mathrm{~mm}$ test disc was made of AISI M3:2, hardened to 64 HRC and polished to a circumferential surface finish of $\mathrm{Ra}=0.08 \mu \mathrm{m}$. The pin was provided with a $\emptyset 6.35$ ball in 440-C stainless steel with a hardness of $62 \mathrm{HRC}$. The test was carried out with a constant load of $16 \mathrm{~N}$ and a rotational velocity of $0.2 \mathrm{~mm} / \mathrm{s}$. The sliding contact was fully immersed in lubricant during testing. The test parameters result in an initial maximum Hertzian contact pressure of approximately $1660 \mathrm{MPa}$. The low sliding velocity used in the test greatly reduces the influence of frictional heating in the 
sliding contact during testing. An external heat source increased the temperature in the test chamber by $6^{\circ} \mathrm{C} / \mathrm{min}$ to a maximum of $350^{\circ} \mathrm{C}$ during the test. The slow temperature increase ensured homogenous heating of the workpiece. The temperature in the test chamber was measured with a thermocouple during testing.

\section{Four-ball test}

Characterization of the wear behavior and the load bearing capacity of the different lubricants was done with a four-ball test. For evaluation of the wear behavior of the lubricants, the four-ball test test was conducted with a load of $300 \mathrm{~N}$, a test duration of 1 hour and a rotational speed of 1420 RPM. Evaluation of the load bearing capacity was done by conducting a series of tests with a 1 minute test duration with increasing test loads until welding of the test specimen was achieved (weld load). The pass load was similarly evaluated with the highest test load applied without welding of the test specimens throughout the test. The load was increased by $200 \mathrm{~N}$ per test. Both test series were conducted with $\emptyset 12.7 \mathrm{~mm}$ balls of $100 \mathrm{Cr} 6$ and approximately $12 \mathrm{ml}$ of liquid lubricant. The test specimens were cleaned in an ultrasonic bath with a Tickopur TR 13 cleaning agent at $60^{\circ} \mathrm{C}$ prior to testing. The developed wear scars on the three stationary balls were evaluated with an optical microscope. The average wear scar diameter was determined by measurement of the transversal and the longitudinal wear scar diameter 
Thermo-gravimetric/differential thermal analysis (TG/DTA)

The present study takes reference in the tribochemical interaction between the test lubricants and the tool material, as an initial characterization of the function of the lubricant in the tribosystem. The thermal and tribochemical properties of the lubricants were characterized by thermos-gravimetric/differential thermal analysis with a NETZSCH STA 449 C thermo-microbalance. Two test series were carried out. In the first test series, thermal analysis was performed on $500 \mathrm{mg}$ AISI M3:2 tool steel powder mixed with the test lubricants. In the second case, the thermal analysis was carried out with 75 mg of each test lubricant separately. The particle size of the tool steel powder used for the test was in the range of $0.005-0.4 \mathrm{~mm}$. Each sample was transferred into an alumina crucible and heated to $550^{\circ} \mathrm{C}$, with a $10^{\circ} \mathrm{C} / \mathrm{min}$ heating rate. The two tests were carried out in an argon atmosphere with a gas flow of $50 \mathrm{ml} / \mathrm{min}$ and in dry air with a gas flow of $43 \mathrm{ml} / \mathrm{min}$ of nitrogen and $7 \mathrm{ml} / \mathrm{min}$ of oxygen, respectively. 


\section{Analysis of lubricant composition with XRF}

Six commercially available lubricants with different formulations were selected for the presented punching experiment. An overview of the selected lubricants is shown in table 1.

Table 1: General overview of the lubricants used for the blanking experiment.

\begin{tabular}{|c|c|c|c|}
\hline Name & $\begin{array}{c}\text { Lubricant } \\
\text { manufacturer }\end{array}$ & Description & $\begin{array}{l}\text { Kinematic } \\
\text { viscosity at } \\
40^{\circ} \mathrm{C}(\mathrm{cSt})\end{array}$ \\
\hline Illoform TDN 81 & Castrol & Highly chlorinated paraffin oil & 170 \\
\hline Illoform PN 226 & Castrol & $\begin{array}{l}\text { Medium chlorinated paraffin oil } \\
\text { with S-, P-, ester-additives and } \\
\text { ZDDP }\end{array}$ & 67 \\
\hline SF $125 \mathrm{~A}$ & Rhenus & $\begin{array}{l}\text { Mineral oil with Ca-, P- and S- } \\
\text { additives }\end{array}$ & 125 \\
\hline $\begin{array}{l}\text { Montgomery DB } \\
4265\end{array}$ & FUCHS & $\begin{array}{l}\text { Mineral oil with calcium } \\
\text { carbonate and S-additives. } \\
\text { Diluted 1:6 with water }\end{array}$ & 2 \\
\hline DROSERA MS 5 & Total & $\begin{array}{l}\text { Multipurpose machine oil } \\
\text { containing triphenyl phosphate }\end{array}$ & 5 \\
\hline Paraffin Oil & Carl Roth & Pure, high viscosity paraffin oil & 75 \\
\hline
\end{tabular}

A preliminary evaluation of the elemental composition of the different lubricants was made with X-ray fluorescence (XRF). This was done in order to characterize the overall lubricant content, since the exact lubricant formulation is normally not disclosed by the manufacturer. Detailed knowledge about the specific additive package of the different lubricants is valuable in order to understand the function of the lubricant in metal forming operations. The compositions of the lubricants were evaluated with an Oxford Maxxi 6 
X-ray fluorescence analyzer, where the most common elements used in lubricant additives (EP, AW, FM) were surveyed, see table 2 .

Table 2: Elemental composition of the lubricants used for the blanking experiment. Values are given in counts per second (CPS) in an X-ray fluorescence analyzer.

\begin{tabular}{|l|c|c|c|c|c|c|c|c|}
\hline \multirow{2}{*}{\multicolumn{1}{c|}{ Name }} & \multicolumn{7}{|c|}{ Elements (CPS) } \\
\cline { 2 - 10 } & Ba & Br & Ca & Cl & P & S & Mo & Zn \\
\hline Illoform TDN 81 & - & - & - & 6631 & 113 & 142 & - & - \\
\hline Illoform PN 226 & - & - & 61 & 4381 & 87 & 153 & - & 2400 \\
\hline SF 125 A & - & - & 4049 & - & 49 & 556 & - & - \\
\hline Montgomery DB 4265 & - & - & 793 & - & 18 & 16 & - & - \\
\hline DROSERA MS 5 & - & - & - & - & - & - & - & - \\
\hline Paraffin oil & - & - & - & - & - & - & - & - \\
\hline
\end{tabular}

No calibration standards were available for the different lubricant additives, meaning that an exact quantification of each lubricant additive was not possible. Evaluation of the counts per second (CPS) for each element allows for a qualitative evaluation of the elemental composition of the lubricants as well as giving a relative comparison of the quantity of each element. The XRF measuring technique has limited applicability for determining the content of elements with low atomic mass. Commonly used lubricant additives such as $\mathrm{Mg}$ and $\mathrm{B}$ compounds are thus not detectable with XRF. The XRF analysis is therefore used as a preliminary survey method for evaluation of the content of common film forming additives like $\mathrm{Cl}, \mathrm{P}$ and $\mathrm{S}$ in the lubricants.

\section{Numerical modeling of the punching process}

FE analysis of the punching operation was made as a coupled thermo-mechanical model with the commercial software LS-DYNA, where the punching operation was modeled 
with an axisymmetric configuration. An overview of the modeled tool setup is shown in fig. 2, and the input parameters are included in table 3 .

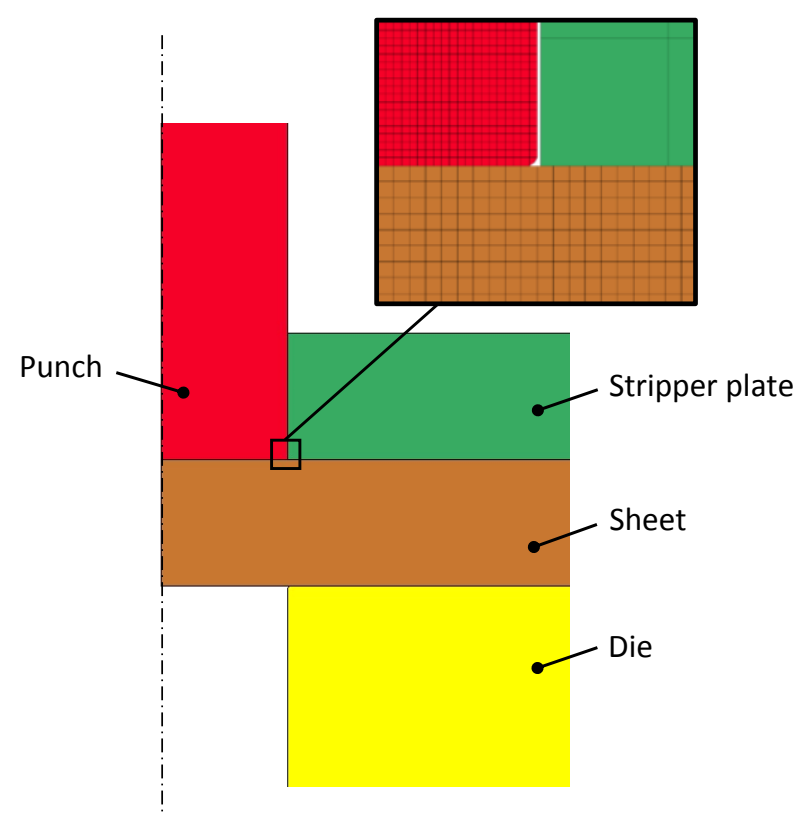

Figure 2: Numerical model with initial mesh shown around the punch corner in the detail.

Table 3: Input parameters for numerical simulation.

\begin{tabular}{|c|c|c|c|}
\hline & $\begin{array}{c}\text { Punch (AISI } \\
\text { M3:2) }\end{array}$ & $\begin{array}{l}\text { Blanking Die } \\
\text { (1.3343 HSS) }\end{array}$ & $\begin{array}{c}\text { Sheet material } \\
\text { (EN 1.4301) }\end{array}$ \\
\hline $\begin{array}{l}\text { Initial temperature } \\
\left({ }^{\circ} \mathrm{C}\right)\end{array}$ & 20 & 20 & 20 \\
\hline $\begin{array}{l}\text { Heat capacity } \\
(\mathrm{J} /(\mathrm{kg} \cdot \mathrm{K}))\end{array}$ & 420 & 460 & 500 \\
\hline $\begin{array}{l}\text { Thermal conductivity } \\
(\mathrm{W} /(\mathrm{m} \cdot \mathrm{K}))\end{array}$ & 24 & 27 & 15 \\
\hline $\begin{array}{l}\text { Heat transfer } \\
\text { coefficient } \\
\left(\mathrm{kW} /\left(\mathrm{m}^{2} \cdot \mathrm{K}\right)\right)\end{array}$ & 50 & 50 & 50 \\
\hline Density (g/cm $\left.{ }^{3}\right)$ & 7.73 & 8.12 & 7.90 \\
\hline $\begin{array}{l}\text { Elastic modulus } \\
\text { (GPa) }\end{array}$ & 230 & 217 & 200 \\
\hline Coefficient of friction & 0.1 & 0.1 & 0.1 \\
\hline Poisson's ratio & 0.3 & 0.3 & 0.3 \\
\hline
\end{tabular}


In the FE model, the forming tools were modeled as rigid steel tools, whereas the sheet material was modeled as a plastic material characterized by a Ludwig formulation $(\sigma=$ $\left.1339 \varepsilon^{0.594}+231[\mathrm{MPa}]\right)$, which was determined by tensile testing. The sheet material was discretized with a quadrilateral mesh with an element size of $0.025 \mathrm{~mm}$. For the FE analysis of the blanking operation a rounding radius of $0.002 \mathrm{~mm}$ was applied to the edge of the punch and the edge of the die in order to avoid localized damage due to sharp contacts in the interfaces between tools and the sheet material. A remeshing algorithm was furthermore applied in the numerical model to compensate for the large localized deformation of the mesh in the shear band region. Ductile fracture of the sheet material was modeled with a simple critical shear stress criterion, which by evaluation of the punch force and the morphology of the sheared edge was found to give an accurate description of the ductile fracture occurring in the punching process. Element deletion was initiated at a shear stress of $1300 \mathrm{MPa}$ in the applied fracture model. Thermal coupling is maintained between the punch surface and the sheared surface. 


\section{Experimental results}

\section{Punching tests}

The punching test was conducted with a number of different liquid lubricants for evaluation of the lubricant performance. Fig. 3. shows the results of the punching test by the backstroke force as a function of the number of strokes for the different lubricants. Dry conditions are also included for reference.

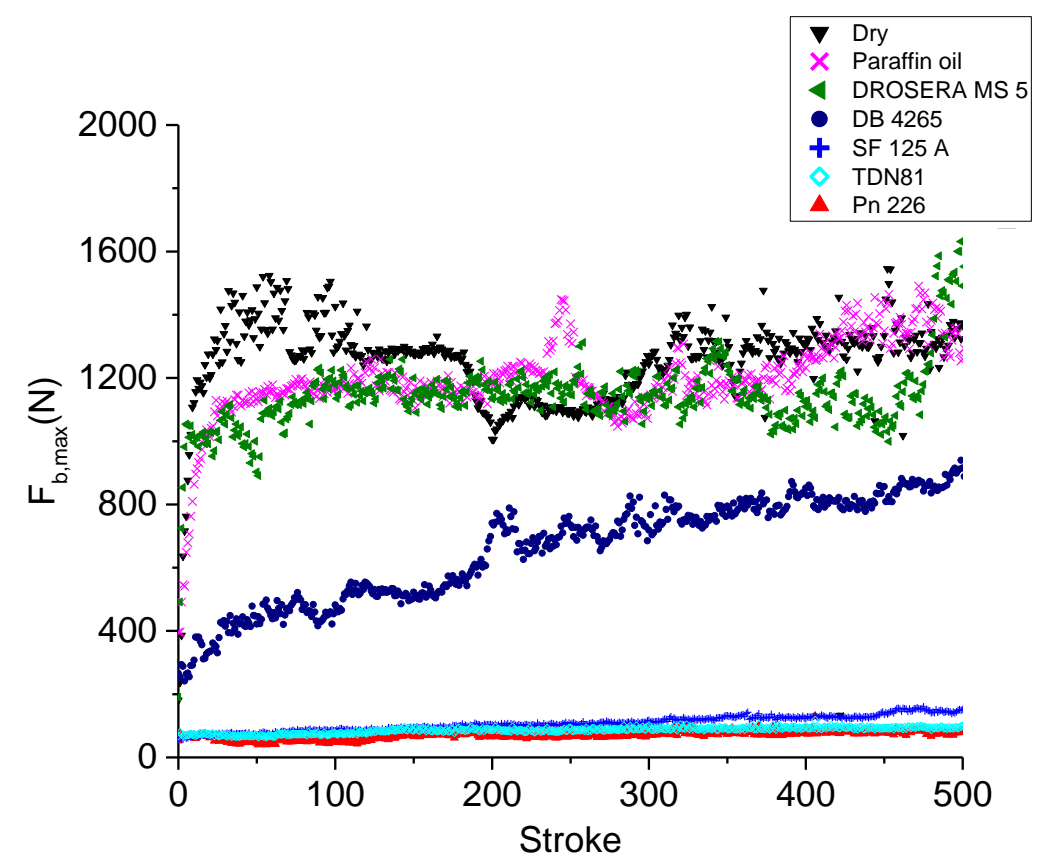

Figure 3: Backstroke force as function of number of strokes for the tested lubricants and under dry conditions.

The development of the backstroke force under dry conditions is found to reach saturation approximately within the first 30 strokes. In the subsequent strokes, the backstroke force is found to fluctuate around an average value of approximately $1300 \mathrm{~N}$. The stabilization 
of the backstroke force is attributed to a saturation of the pickup on the punch surface. The test series conducted with the low viscosity oil Drosera MS 5 and the pure paraffin oil were found to exhibit a similar performance. The DB 4265 lubricant, containing Caand S- based lubricant additives, exhibits a gradually increasing backstroke force within the first 500 strokes. The DB 4265 lubricant is based on a suspension of solid particles in the base oil, which inhibits direct metal-to-metal contact between the punch and the sheet material. This mechanism of lubrication retards the adhesive wear that accumulates on the punch stem. A common characteristic of the lubricants, which exhibited poor performance in the punch test, is low viscosities and either a low content of film forming additives or no additives at all, as evaluated with XRF. The two chlorinated paraffin oils, TDN81 and Pn 226, were found to exhibit excellent lubricating ability in the blanking test with a consistently low backstroke force throughout the 500 strokes. The SF $125 \mathrm{~A}$ lubricant, containing $\mathrm{Ca}$-, $\mathrm{P}$ - and $\mathrm{S}$-additives, is found to have a comparable performance, however, with a small increase in the backstroke force after approximately 250 strokes. An overview of the surface structure of the punches after testing is shown in fig. 4. 


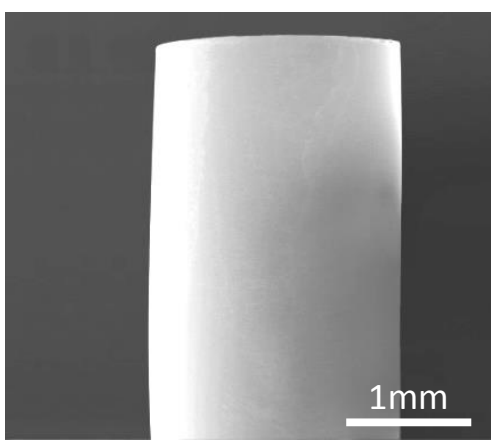

(a)

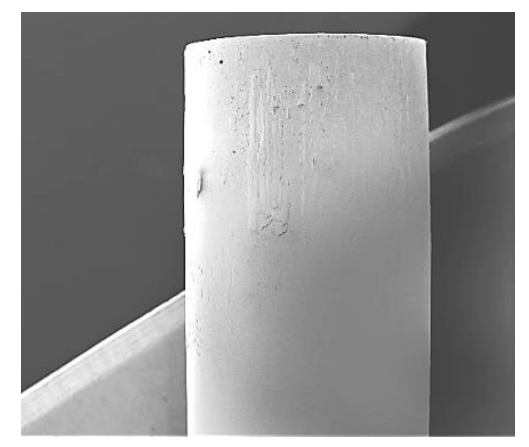

(c)

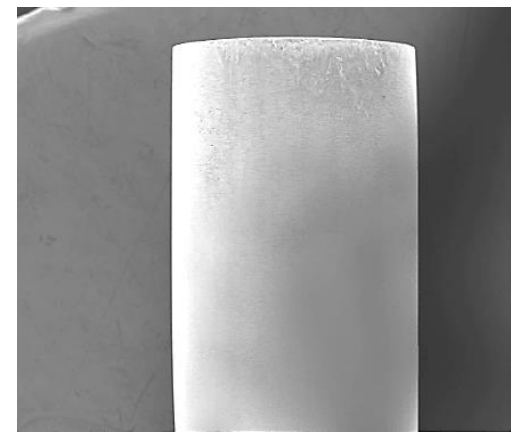

(e)

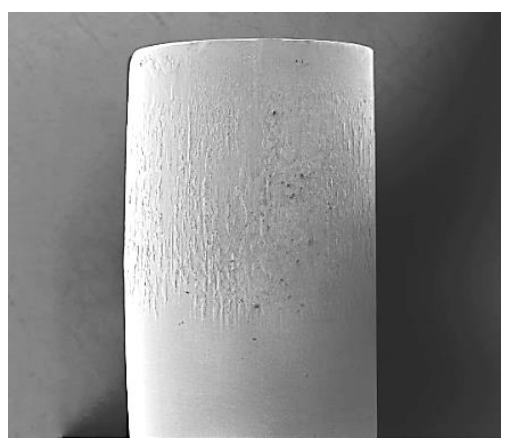

(b)

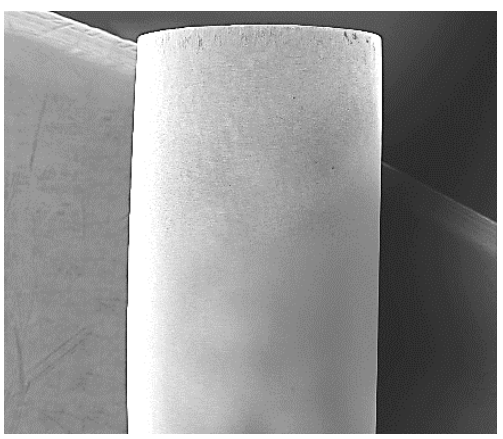

(d)

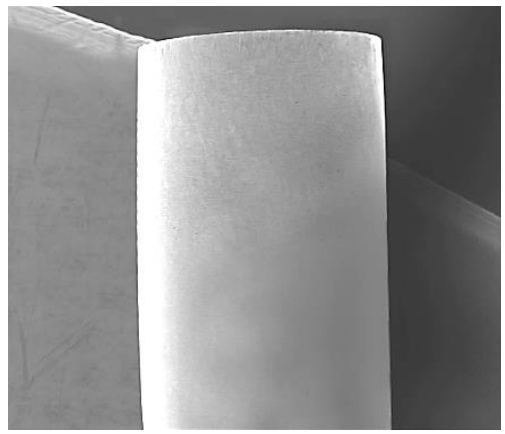

(f)

Figure 4: SEM micrographs of the punch surface of (a) a new punch and (b-f) punches after testing with different lubricants: (b) DB 4265, (c) Drosera MS 5, (d) Pn226, (e) SF125 and (f) TDN81. 
From inspection of the surface structure of the punches after testing, it is seen that the three highly additivated lubricants, which resulted in low backstroke forces in the punching test, have resulted in minor levels of pickup of workpiece material around the punch tip. In contrast to this the test series conducted with the DB 4265 and the Drosera MS 5 lubricants are found to have a large amount of accumulated pickup of workpiece material on the punch stem, corresponding to a large increase in the measured backstroke force during the test.

\section{Four-ball test}

An overview of the wear characteristics and the determined weld load and pass load for the tested lubricants using the four-ball test is shown in fig. 5a and fig. 5b, respectively.

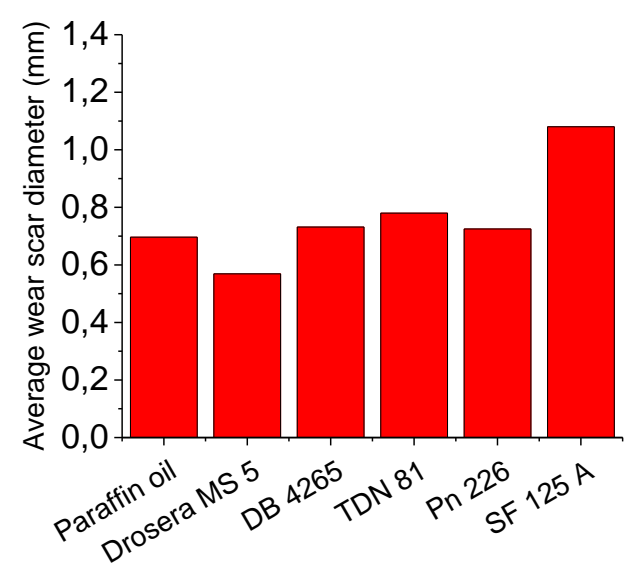

(a)

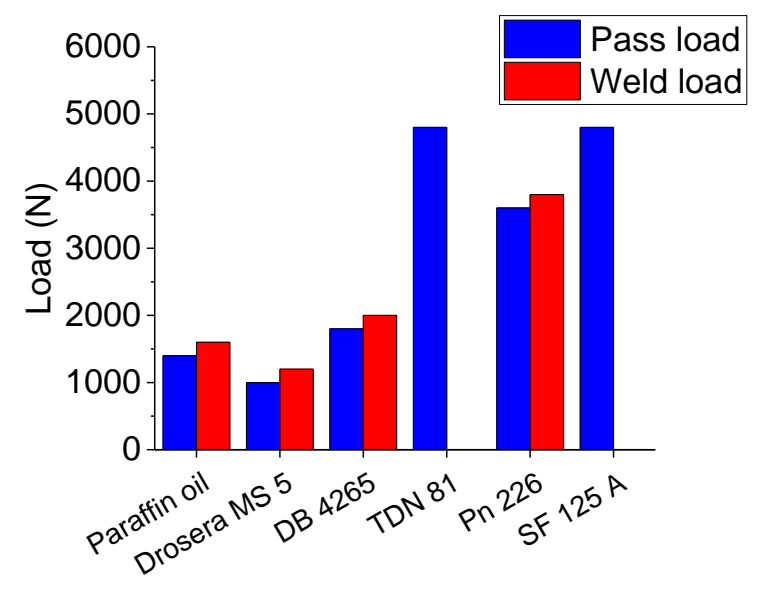

(b)

Figure 5: Characterization of the wear behavior and the load bearing capacity of the tested lubricants in the four-ball test. The results are shown by (a) developed wear scar diameter and (b) weld load and pass load. 
From fig. 5a it is seen that the wear scar diameters generated during the four-ball test ranges from $0.57-0.73 \mathrm{~mm}$ for most of the tested lubricants. The test results for SF $125 \mathrm{~A}$ are however found to result in a substantially larger wear scar diameter. While the different lubricants exhibited a widely varying performance in the punching test, the developed wear scar diameter indicates a comparable wear performance in the four-ball test. Evaluation of the load bearing capacity however reveals a substantial difference in the tribological properties of the lubricants. The tested lubricants with high weld loads in the four-ball test correspond to the lubricants with excellent results in the punching test; namely those lubricants, which inhibited adhesive wear on the punch stem. Conversely, the lubricants with low weld loads, in the range of 1600-2000 N, are those providing poor lubrication in the punching test. The weld load of TDN 81 and SF 125 A could not be determined for the present study as the loads were found to exceed the maximum capacity of the experimental equipment. The lubricants with high load bearing capacities are found to form tribofilms in the interface between the workpiece and the punch, which retards the mechanism of adhesive wear on the punch surface, as e.g. seen with the chlorinated paraffin oil. The load bearing capacity of the lubricant is therefore identified as one of the primary tribological lubricant properties for blanking processes, where the affinity to adhesion of workpiece material to the punch poses a major tribological issue. 
High temperature pin-on-disc test

The influence of thermal conditions on the tribological properties of the lubricants was studied with the high temperature pin-on-disc test. The main results are summarized in fig. 6, where an average coefficient of friction of two test repetitions is shown as a function of temperature.

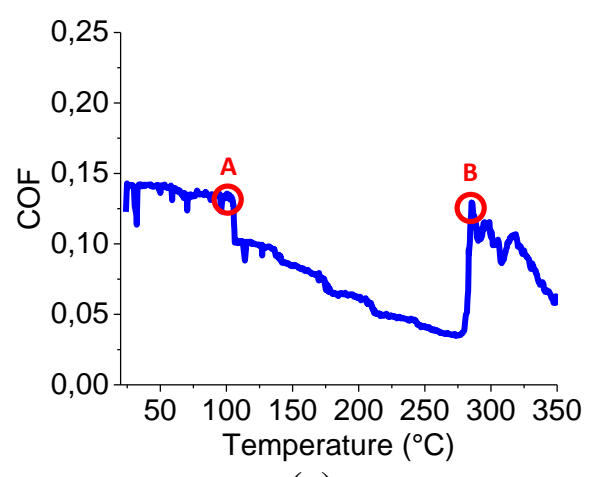

(a)

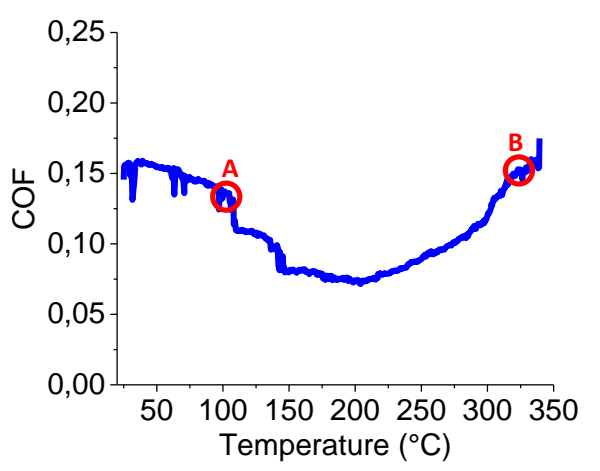

(b)

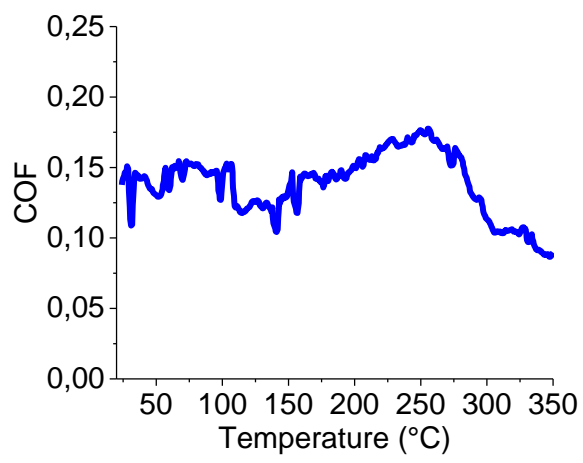

(c)

Figure 6: $\mathrm{COF}$ as a function of the test temperature in pin-on-disc testing with (a) Pn226, (b) Drosera MS 5 and (c) Paraffin oil.

As examples of the tested lubricants containing film forming additives, the Pn 226 and the Drosera MS 5 lubricants are found to exhibit a temperature interval, where a lower 
$\mathrm{COF}$ is measured due to thermal activation of the lubricant additives. This temperature interval is defined by point (A), where the active additive species in the lubricant are adsorbed on the surface of the metal, forming a tribofilm that lowers the COF and point (B), where a loss of the lubricating properties occurs due to thermal degradation of the lubricant. These transition temperatures indicate the working range of the lubricant, where properties of boundary lubrication are exhibited. The pure paraffinic base oil is conversely found to have an increasing COF at elevated temperatures due to thinning of the lubricant. After the initial increase in friction, a large decrease in the measured COF is seen at approximately $270^{\circ} \mathrm{C}$, when nearing the boiling point of the lubricant, as seen in the following TG/DTA results. 
Thermo-gravimetric/differential thermal analysis (TG/DTA)

Evaluation of the lubricant properties at elevated temperatures was furthermore done with TG/DTA, see fig. 7. The TG/DTA was conducted in dry air as well as in an inert argon atmosphere in order to study the influence of oxygen as well as a limitation of oxidative degradation of the lubricants.

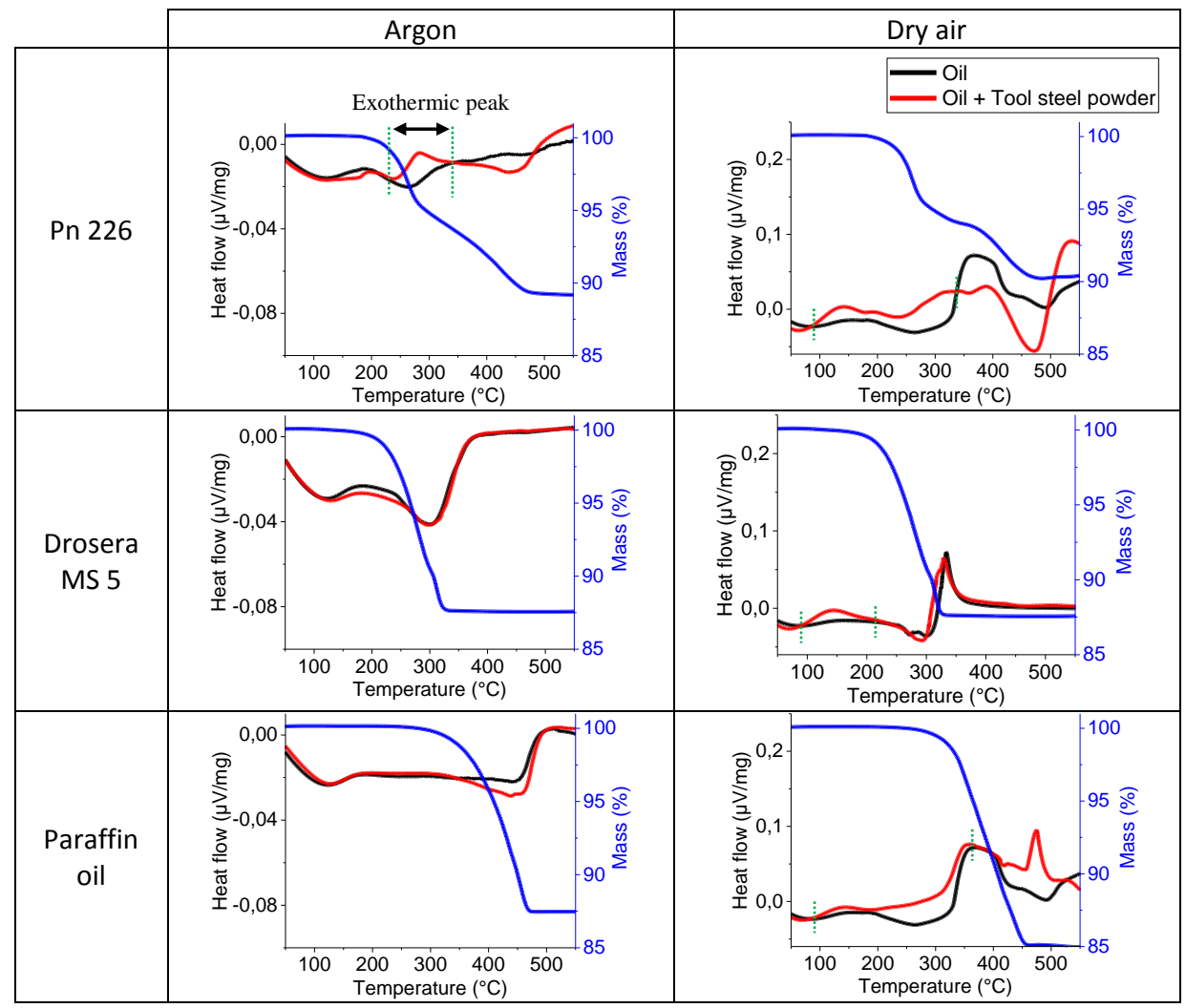

Figure 7: TG/DTA thermograms of the tested lubricants.

The thermograms established from testing of the pure lubricants and testing of mixtures of the tool steel powder and lubricant were used for assessment of the transition temperature, where activation of the lubricant additives was initiated. This was evaluated 
by superposition of the two thermograms [25]. A summary of the critical transition temperatures is shown in table 4.

Table 4: Overview of the transition temperatures of the tested lubricants

\begin{tabular}{|l|c|c|c|c|}
\hline & $\begin{array}{l}\text { Temperature } \\
\text { of initial } \\
\text { chemical } \\
\text { reaction }\left[{ }^{\circ} \mathrm{C}\right]\end{array}$ & $\begin{array}{l}\text { Temperature } \\
\text { of lubricant } \\
\text { breakdown } \\
{\left[{ }^{\circ} \mathrm{C}\right]}\end{array}$ & $\begin{array}{l}\text { Temperature } \\
\text { interval of first } \\
\text { exothermic peak } \\
{\left[{ }^{\circ} \mathrm{C}\right] \text { (Ar) }}\end{array}$ & $\begin{array}{l}\text { Temperature } \\
\text { interval of first } \\
\text { exothermic peak } \\
{\left[{ }^{\circ} \mathbf{C}\right] \text { (dry air) }}\end{array}$ \\
\hline Illoform TDN 81 & 101 & 287 & $151-256$ & - \\
\hline Illoform PN 226 & 104 & 285 & $223-339$ & $89-339$ \\
\hline SF 125 A & 109 & 309 & $125-195$ & $108-212$ \\
\hline $\begin{array}{l}\text { Montgomery DB } \\
\text { 4265 }\end{array}$ & 229 & - & - & - \\
\hline DROSERA MS 5 & 105 & 319 & - & $90-226$ \\
\hline Paraffin oil & - & - & - & $94-369$ \\
\hline
\end{tabular}

The thermogram for Pn 226 and tool steel powder mixture reveals an exothermic peak at a temperature of $223-339^{\circ} \mathrm{C}$ in the inert atmosphere, i.e. Ar. The first exothermic peak in dry air is, however, seen in the temperature range of $89-339^{\circ} \mathrm{C}$. The widening of the temperature range of the exothermic peak is possibly due to the influence of oxygen on the compound additive package of the lubricant, as certain groups of lubricant additives, e.g. certain S-based additives, only display a tribological function with the presence of oxygen [8]. The thermogram for pure paraffinic base oil reveals an initial exothermic peak in the temperature range of $94-369^{\circ} \mathrm{C}$ in dry air, while no major reaction peaks were found in Ar. This behaviour is attributed to the oxidative degradation of the lubricant at elevated temperatures. This is indicative of the sensitivity of the TG/DTA technique 
towards a range of different physical and chemical phenomena occurring simultaneously during the heating cycle, highlighting the importance of assessing the lubricants in varying atmospheres for evaluation of the thermal stability and the tribological properties of the lubricant. The TG/DTA is therefore used as a supplementary technique for assessment of the lubricant properties at elevated temperatures. This encompasses a supplementary method for determining the transition temperatures of the film forming additives and the thermal stability of the lubricant. 


\section{Numerical modelling of the punching test}

Punching operations are commonly found to develop highly localized temperature fields and transient temperatures peaks, which makes it difficult to characterize the process temperatures with conventional measurement techniques, e.g. thermocouples or thermographic measurements. Assessment of the temperature development in the forming tool and the sheet material during the punching operation in the present study is therefore done with a coupled thermo-mechanical FE simulation. The simulated temperature field during a punching operation is shown in fig. $8 \mathrm{a}$, where point 1 and point 2 are highlighted. Point 1 is inside the punch $0.3 \mathrm{~mm}$ from the tip, while point 2 is in the shear band region at the center of the sheet at the start of the test. The vertical position of point 2 varies during the test as the sheet material is plastically deformed into the blanking die. 


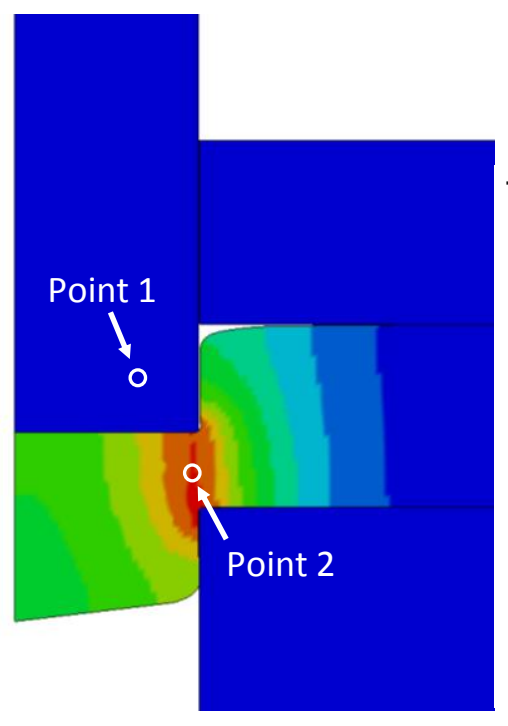

Temperature

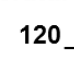

110

100

90

80

70

60

50

40

30

20

(a)

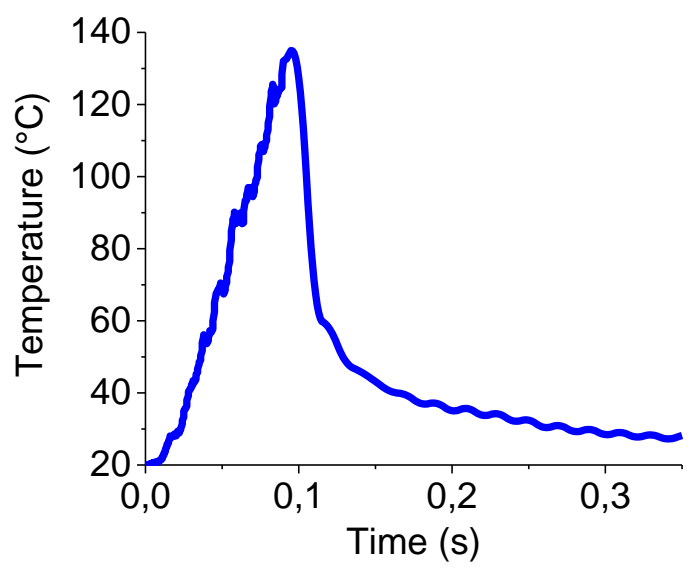

(b)

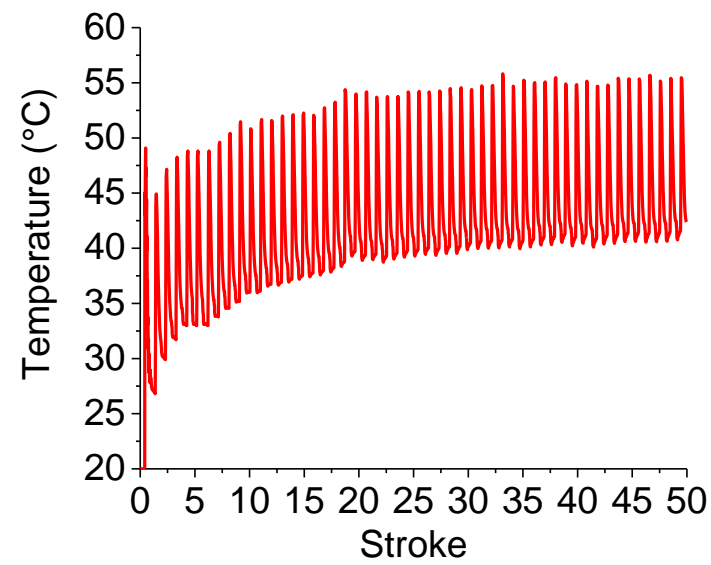

(c)

Figure 8: Thermo-mechanical FE simulation of temperature showing (a) the temperature distribution in the tools and workpiece, (b) temperature development in point 2 during stroke number 1, and (c) temperature development in point 1 during the first 50 strokes.

The temperature development in the sheared surface, see fig. $8 \mathrm{~b}$, shows a high temperature peak during the forward punch stroke, followed by a large dissipation of the generated heat after approximately $0.1 \mathrm{~s}$. The peak temperature ranges locally between $135-150^{\circ} \mathrm{C}$ in the shear band region. Fig. 8c shows development of the punch temperature in point 1 
during the first 50 strokes. The transient temperature peak and the short time of contact between the punch and the sheet material result in minor heat transfer to the punch, which is found to stabilize after approximately 40 strokes. The peak temperature in the interface between the punch and the sheet material governs the tribological behaviour of the lubricant, as seen in the pin-on-disc test and the TG/DTA. The lubricants providing excellent lubrication in the punching test are therefore characterized by having high load bearing capacities combined with an applicable thermal working range, where the peak temperature in the punching process ensures the activation of the lubricant additives in the punch/workpiece interface in order to inhibit the development of pickup of workpiece material.

\section{Conclusion}

The performance of different lubricants was evaluated with a punching test. A clear correlation between the development of pickup of workpiece material on the punch stem and the measured backstroke force was confirmed in accordance with literature. Process temperatures were characterized by numerical simulation. Combined analysis of the lubricating action of common EP additives was made with TG/DTA and a high temperature pin-on-disc test, which showed that the effective, additivated lubricants exhibit a temperature interval where a low COF is measured. This temperature interval is 
defined by an initial activation temperature and a second transition temperature, where a loss of the lubricating ability occurs due to thermal degradation. Analysis of the tribochemical properties of the tested lubricants furthermore revealed that an applicable temperature range and a high load bearing capacity are central lubricant properties necessary for ensuring sufficient lubricating ability for punching and blanking operations. Characterization of these essential lubricant properties allows for a selection of alternative, environmentally friendly lubricants suitable for replacing the hazardous chlorinated paraffins often used in tribologicallly severe manufacturing processes. Based on this methodology, the presented study highlighted the possibility to replace chlorinated paraffins for punching and blanking operations with a mineral oil with an additive package based on Ca-, P- and S-additives.

\section{Acknowledgements}

Daniel Cardenas Del Rio is gratefully acknowledged for his contribution to the presented work. The work is supported by the Danish Council for Independent Research [grant no. DFF - 4005-00130]. The work was furthermore conducted within the frameworks of the ELSAT2020 project supported by the French Ministry of Higher Education and Research, the French National Center for Scientific Research (CNRS), the Hauts de France Region 
and the Carnot Arts Institute. The authors gratefully acknowledge the support of these institutions.

\section{References}

[1] Millard A, Gasnier J. Performance evaluation of lubricants during blanking. CETIM, Senlis Cedex 1995.

[2] Pfaff KO. Über das Lochen austenitischer rostfreier Feinbleche. 1972.

[3] Lind L, Peetsalu P, Adoberg E, Veinthal R, Kulu P. Description of punch wear mechanism during fine blanking process. Proc 7th Int Conf DAAAM Balt Ind Eng 2010:504-9.

[4] Olsson DD, Bay N, Andreasen JL. Lubricant test for punching and blanking. JSTP Journal, Spec Issue 2003;44 no.: 50.

[5] Olsson DD, Bay N, Andreasen JL. Analysis of Pick-Up Development in Punching. CIRP Ann 2002;51:185-90. doi:10.1016/S0007-8506(07)61496-6.

[6] Olsson DD, Bay N, Andreasen JL. Studies of lubricants and punch design in punching of stainless steel. Proc Int Conf Recent Adv Manuf Use Tools Dies Stamp Steel Sheets 2005.

[7] Schmidt RA, Birzer F, Op de Hipt M. Tribologie beim Scherschneiden und Feinschneiden. Tribol Und Schmierungstechnik 2005;52:42-54.

[8] Klocke F, Maßmann TC, Zeppenfeld C, Schmidt RA, Schulz J, Mumme F. Fineblanking with non-chlorinated lubricants. Tribol Und Schmierungstechnik 2008;55:33-8.

[9] Hogmark S, Bengtsson K, O. Vingsbo. Wear of steel punches. Scand J Metall 1981;10.

[10] Won C, Kim H, Song Y, Chung G, Lee S, Yoon J. Abrasive Wear in Punching Pin with Cryogenic Treatment for GPa-Grade Steels. Int J Precis Eng Manuf 2018;19:1179-86. doi:10.1007/s12541-018-0139-3.

[11] Çöl M, Kir D, Erişir E. Wear and blanking performance of AlCrN PVD-coated punches. Mater Sci 2013;48:514-20. doi:10.1007/s11003-013-9532-3.

[12] Lind L, Peetsalu P, Sergejev F. Wear of different PVD coatings at industrial fine-blanking field tests. Mater Sci 2015;21:343-8. doi:10.5755/j01.ms.21.3.7249.

[13] Klocke F, Raedt H-W. Formulation and testing of optimised coating properties with regard to tribological performance in cold forging and fine blanking applications. Int J Refract Met Hard Mater 2001;19:495-505. doi:10.1016/S0263-4368(01)00029-4.

[14] Straffelini G, Bizzotto G, Zanon V. Improving the wear resistance of tools for stamping. 
Wear 2010;269:693-7. doi:10.1016/j.wear.2010.07.004.

[15] Podgornik B, Zajec B, Bay N, Vižintin J. Application of hard coatings for blanking and piercing tools. Wear 2011;270:850-6. doi:10.1016/j.wear.2011.02.013.

[16] Klocke F, Raedt HW. Formulation and testing of optimised coating properties with regard to tribological performance in cold forging and fine blanking applications. Int J Refract Met Hard Mater 2001;19:495-505. doi:10.1016/S0263-4368(01)00029-4.

[17] Kitamura K, Makino T, Nawa M, Miyata S. Tribological effects of punch with microdimples in blanking under high hydrostatic pressure. CIRP Ann - Manuf Technol 2016;65:249-52. doi:10.1016/j.cirp.2016.04.133.

[18] Jayadas NH, Prabhakaran Nair K, Ajithkumar G. Vegetable Oils as Base Oil for Industrial Lubricants: Evaluation Oxidative and Low Temperature Properties Using TGA, DTA and DSC. Proc. World Tribol. Congr. III, American Society of Mechanical Engineers; 2005, p. 539-40. doi:10.1115/wtc2005-63893.

[19] Haglund BO, Enghag P. Characterization of lubricants used in the metalworking industry by thermoanalytical methods. Thermochim Acta 1996;282-283:493-9. doi:10.1016/0040-6031(96)02825-0.

[20] Matveevsky RM, Buyanovsky IA. Investigation of the transition temperatures of lubricants under friction of steels. Eurotrib 81 3rd Int. Tribol. Congr. Vol. Iii Lubr. Their Appl., 1982, p. 171-9.

[21] Matveevsky RM. Chemical modification of friction surfaces in boundary lubrication. ASLE Trans 1982;25:483-8. doi:10.1080/05698198208983117.

[22] Matveevsky RM. Evaluation of temperature stability of a lubricant film on rubbing surfaces. Tribology 1968;1:115-7. doi:10.1016/S0041-2678(68)80349-5.

[23] Matveevsky RM. The temperature of tribochemical reaction between e.p. additives and metals. Tribology 1971;4:97-8. doi:10.1016/0041-2678(71)90139-4.

[24] Matveevsky RM. Problems of boundary lubrication. Tribol Int 1995;28:51-4. doi:10.1016/0301-679X(95)99494-6.

[25] Kawamura M, Fujita K. Organic sulphur and phosphorus compounds as extreme pressure additives. Wear 1981;72:45-53. doi:10.1016/0043-1648(81)90282-9.

[26] Wan Y, Xue Q. Effect of phosphorus-containing additives on the wear of aluminum in the lubricated aluminum-on-steel contact. Tribol Lett 1996;2:37-45. doi:10.1007/BF00182546.

[27] Kawamura M. The correlation of antiwear properties with the chemical reactivity of zinc dialkyldithiophosphates. Wear 1982;77:287-94. doi:10.1016/0043-1648(82)90054-0.

[28] Møller PB, Petrushina IM, Christensen E, Bjerrum NJ, Høj J, G. Kann, et al. Chemical 
Interactions between Extreme Pressure Lubricants and Stainless Steel during Ironing Procedure. Nord '98 Proc 8th Int Conf Tribol 1998;2:7-10.

[29] Petrushina I., Christensen E, Bergqvist R., Møller P., Bjerrum N., Høj J, et al. On the chemical nature of boundary lubrication of stainless steel by chlorine- and sulfurcontaining EP-additives. Wear 2000;246:98-105. doi:10.1016/S0043-1648(00)00503-2. 